\title{
A BABEL DO FUTEBOL: ATLETAS INTERCULTURAIS E TORCEDORES ULTRAS
}

\author{
José Paulo Florenzano \\ Professor de Antropologia da Pontifícia Universidade Católica de São Paulo e \\ doutor em Antropologia Social pela Faculdade de Filosofia, Letras \\ e Ciências Humanas da Universidade de São Paulo.
}

\section{Resumo}

A crise de credibilidade na arbitragem, as cenas de guerrilha urbana nos estádios, a perda dos parâmetros financeiros na gestão das esquadras, somadas à denominada "invasão dos estrangeiros", representada em especial pelos atletas africanos, inter-relacionavam-se para compor a fórmula explosiva do calcio às vésperas do Terceiro Milênio. A partir de uma perspectiva teórica informada pelo quadro de referência da sociologia e da antropologia do esporte, o texto aborda esta conjuntura histórica e destaca as questões entrelaçadas do imaginário racista das torcidas ultras de extrema direita - exacerbado pelo avanço do futebol global - e a destreza simbólica dos jogadores negros, refletida na dupla habilidade de se desvencilhar das representações negativas e de articular novas significações sociais para o jogo.

\section{Pallavross-chave}

ultras $\bullet$ futebol global $\bullet$ racismo $\bullet$ violência $\bullet$ atletas africanos.

Correspondência

Faculdade de Ciências Sociais - PUC/SP

Rua Monte Alegre, 1.104

05014-000 - Perdizes - São Paulo - SP

E-mail: jpflorenzano@uol.com.br 


\title{
THE BABEL OF FOOTBALL: \\ INTERCULTURAL ATHLETES AND \\ THE ULTRA FANS
}

\author{
José Paulo Florenzano \\ Professor of Anthropology at Pontifícia Universidade Católica de São Paulo \\ and Doctor in Social Anthropology, Faculdade de Filosofia, Letras e \\ Ciências Humanas of the Universidade de São Paulo
}

\begin{abstract}
The crisis concerning the lack of credibility among referees, scenes of urban guerrilla warfare in the stadiums, financial parameters for managing the teams that have fallen by the wayside, together with the so-called "foreign invasion", mostly represented by African athletes, were inter-woven into an explosive formula for the calcio of the dawn of the Third Millennium. Using a theoretical perspective informed by the framework of sociological and anthropological references for the sport, the text discusses this historical crossroads and underscores interrelated questions of the racist imagination of the extreme right "ultras" (exacerbated by the advancement of global football), and the symbolic dexterity of black players, reflected in their dual ability to extricate themselves from negative representations and articulate new social meanings for the game.
\end{abstract}

\section{Keywords}

utras $\bullet$ global football $\bullet$ racism $\bullet$ violence $\bullet$ African athletes.

Contact

Faculdade de Ciências Sociais - PUC/SP

Rua Monte Alegre, 1.104

05014-000 - Perdizes - São Paulo - SP

E-mail: jpflorenzano@uol.com.br 
Apenas dois pontos separavam a Juventus da Lazio na disputa pelo campeonato de 1999/2000. Na penúltima rodada do returno, enquanto a Fênix vencia o Bologna fora de casa pelo placar de 3 a 2, em Turim, a Vecchia Signora batia o Parma por 1 a 0. Todavia, aos 44 minutos do segundo tempo, no escanteio cobrado por Amoroso, o zagueiro Cannavaro fez de cabeça o gol de empate. Gol, no entanto, anulado pelo árbitro De Santis que ora alegava ter encerrado a partida antes da conclusão da jogada, ora mencionava uma suposta falta cometida na área. Os programas esportivos exibiam o lance de vários ângulos, repassavamno diversas vezes em busca de uma tênue evidência de irregularidade, qualquer indício de falta. Mas não havia nada, salvo a perplexidade dos próprios comentaristas. Dessa maneira, a competição, repleta de estrelas do brilho de Ronaldo, Zidane e Baggio, com transações milionárias entre os clubes e transmissões para todos os cantos do planeta, "terminava no caos", sob os protestos violentos dos torcedores da Lazio, convulsionando o centro de Roma em consequência do "scudetto roubado".

Além da arbitragem sob suspeita nos gramados e da torcida exasperada nas ruas, a última edição do calcio no século XX também enfrentava o que a imprensa esportiva do país designava de "invasão dos estrangeiros". ${ }^{2}$ De fato, no curto espaço de cinco anos, desde a aprovação da Lei Bosman, em 15 de dezembro de 1995, o número deles havia aumentado de forma significativa, saltando de sessenta e seis para duzentos e cinquenta. ${ }^{3} \mathrm{O}$ corolário desta presença, segundo La Gazzetta dello Sport, estava na "Babel de línguas e táticas" na qual se transformara o calcio. ${ }^{4}$ A Babel do futebol, no entanto, comportava aspectos

1 Cf. Guerriglia degli ultrà laziali sconvolto il centro di Roma. La Repubblica, 12 de maio de 2000. Cf. A rischio la credibilità del calcio. La Gazzetta dello Sport, 9 de maio de 2000. L'Avvelenata. Guerin Sportivo, 10 -16 de maio de 2000.

2 Cf. La caduta del calcio. La Gazzetta dello Sport, 20 de abril de 2000.

3 Jean-Marc Bosman, meio-campista do Liège, da Bélgica, desejava transferir-se para o Dunquerque, da França. A direção do clube belga lhe propunha redução de salário ao mesmo tempo em que exigia uma quantia elevada para liberá-lo. Sem alternativa, o jogador iniciou, em 1990, uma ação contra o Liège e a Uefa. Cinco anos depois, obteve a vitória na Corte de Justiça da UE. A decisão comportava dois aspectos interligados: o fim da indenização na transferência do jogador de um clube para outro e o fim da cláusula da nacionalidade para os atletas da comunidade europeia.

4 Cf. Dove non spunta più un Rivera. La Gazzetta dello Sport, 20 de abril de 2000. Fechado desde 1964, o mercado de trabalho foi reaberto em 1980. A princípio, apenas um estrangeiro por time, mas, já em 1982, o número passou para dois e, em 1987, para três. Em 1995, a Lei Bosman instituiu a livre circulação para os atletas da UE sem tocar na questão dos extracomunitários. Cada clube podia inscrevê-los em número de cinco, mas escalar somente três por jogo. Em 2000, o atleta nigeriano Prince Ekong Ikpe, da série $\mathrm{C}$, foi à Justiça na Itália contra as regras restritivas. A sentença do Tribunal de Reggio Emilia reconhecera-lhe o direito de exercer a profissão e tornara a distinção entre comunitários e extracomunitários "fora da lei". Cf. Stranieri liberi, uma 
contraditórios, desvelava múltiplas feições, abrigava, ao mesmo tempo, a tensão estabelecida pelo ingresso contínuo e crescente dos forasteiros, vistos como uma terrível ameaça à identidade nacional, e a força do processo global que abalava as fronteiras regionais, abolia os entraves à livre circulação de atletas e rompia os parâmetros financeiros na gestão dos clubes. ${ }^{5}$ Sob este último aspecto, aliás, a transformação afigurava-se tão ampla e perturbadora que até mesmo João Paulo II advertia a respeito dos riscos de uma atividade submersa pelos valores materiais e incapaz de assegurar o "primado do ser sobre o ter". ${ }^{6}$

A classe dirigente, por sua vez, replicava ao santo padre que o dinheiro não trazia infelicidade. ${ }^{7}$ Ademais, argumentava Sergio Cragnotti, a administração profissional dos clubes exigia uma mentalidade inovadora, sempre pronta a "comprar e vender" atletas, renovar e motivar o elenco, livre das amarras impostas pela tradição. Elevado à condição de arauto de uma nova era, o presidente da Lazio sentenciava sem hesitação: "no calcio moderno não existem mais as bandeiras". ${ }^{8}$ Os ultras, no entanto, não se sentiam persuadidos disso e durante os jogos exibiam cartazes com a contra mensagem: "Não ao calcio moderno". 9 Reunidos nas curvas dos estádios, recrutados em todos os estratos sociais, os jovens torcedores autodenominados ultras formavam um movimento dinâmico e multifacetado (Roversi, 1992; Bromberger, 1995), cuja emergência remontava aos últimos anos da década de sessenta, mais precisamente a 1968, quando, nos setores populares do San Siro, no segundo anel do estádio, veio a lume a torcida pioneira do rubro-negro cognominada Fosso dos Leões em alusão ao nome do antigo campo de treinamento do Milan. Vozes dissonantes no teatro do futebol (Bromberger, 1995, p. 263), para compreender suas razões e suas motivações devemos recuar no tempo e refazer, ainda que de forma esquemática, as principais etapas percorridas pelo movimento que elas compõem e animam (Roversi, 1992, p. 37). O caminho, embora cheio de meandros, nos conduzirá de volta aos acontecimentos do campeonato de 1999/2000.

rivoluzione. La Repubblica, 3 de novembro de 2000.

5 A Fifa, a Uefa e os ministros de Esporte dos países membros da União Europeia criticavam a "perda da identidade nacional dos clubes" e propunham a fórmula $6+5$, isto é, um mínimo de seis atletas nacionais no time, contra cinco estrangeiros, comunitários e extracomunitários. Cf. Fifa e Uefa all'UE: “Troppi stranieri, una rovina”. La Gazzetta dello Sport, 10 de novembro de 1999.

6 Cf. Il monito del Papa al calcio dei ricchi. La Gazzetta dello Sport, 9 de maio de 2000.

7 Cf. "I soldi non fanno l'infelicità". La Gazzetta dello Sport, 29 de abril de 2000.

8 Cf. Cragnotti chiude l'era delle "bandieri". La Gazzetta dello Sport, 22 de dezembro de 1999.

9 Cf. Mal di Roma. Guerin Sportivo, 9 - 15 de fevereiro de 2000. 
A análise comporta três aspectos interligados, ou, dito de outra forma, situa a questão no ponto de confluência de três processos simultâneos: em primeiro lugar, o fenômeno ultra insere-se no quadro histórico mais amplo da autonomização da juventude no Ocidente, refletida no advento de inúmeros estilos de vida e formas de sociabilidade (Bromberger, 1995, p. 245); em segundo lugar, participa do clima de radicalização política em curso na Itália, dividida entre a visão de mundo clerical-conservadora representada pela Democracia Cristã, e os ideais progressistas e revolucionários associados ao Partido Comunista (Podaliri; Balestri, 1998, p. 89); por último, mas não menos importante, emerge na esteira do "processo de difusão cultural" deslanchado por hooligans e skinheads, na Inglaterra, a partir da temporada 1966/1967 (Roversi, 1992, p. 42; Costa, 2000, p. 19). Com efeito, os ultras começaram a ocupar e a modificar a paisagem dos estádios adotando e exibindo as principais características introduzidas pelos grupos ingleses, a saber: a delimitação das curvas enquanto espaço exclusivo das facções; a combatividade agressiva direcionada aos agrupamentos rivais; a exaltação da força física e da masculinidade viril, associadas à classe trabalhadora na qual se inseriam os torcedores; o desprezo por qualquer forma de diferença capaz de por em risco a identidade coletiva; a coesão interna tecida ao redor da equipe, apoiada de forma incondicional através de coros e cantos entoados incessantemente no transcorrer de toda a partida (Dunning; Murphy; Williams; 1990). ${ }^{10}$ Conquanto inspirados por tal modelo, os ultras, no entanto, dele se diferenciaram sob vários aspectos, a começar pela complexidade da coreografia encenada nas arquibancadas, baseada em uma ampla gama de sons e cores, na utilização de instrumentos musicais e de recursos pirotécnicos, nas performances artísticas e sofisticadas elaboradas na produção de um "evento espetacular" em torno do qual girava a organização das torcidas e se afirmava a "autonomia dos rituais ultras" (Dal Lago; De Biasi, 1994, p. 79-80). Além disso, as faixas compunham verdadeiros painéis "antropológicos" cujas mensagens versavam sobre as mais diferentes questões, abordadas nos mais variados tons: do protesto político à citação literária, passando pela provocação jocosa, a visão de mundo das curvas exprimia-se nos comentários sobre o escândalo de doping envolvendo as grandes esquadras; nas críticas ao torcedor de poltrona alimentado pelo sistema pay-per-view; ou, ainda, nas ameaças nada veladas às personagens do

${ }^{10}$ Os skinheads tornaram-se atuantes no cenário do futebol a partir de 1967 , incrementando a violência entre os torcedores e acentuando a "oposição a toda forma de diversidade que se apresentasse como ameaçadora à própria identidade: a do homossexual, a do asiático, a do jamaicano ou simplesmente a do pertencimento a outra comunidade local" (Roversi, 1992, p. 39). 
espetáculo, como a dirigida pelos ultras da Lazio ao árbitro da malfadada partida entre Juventus e Parma:

De Santis: a justiça esportiva te absolveu... A nossa te condenou... À morte! ${ }^{11}$

A originalidade da "via italiana" (Roversi, 1992, p. 42), contudo, não se esgotava na magnificência das coreografias ou na pluralidade temática das faixas. Ela incluía, sobretudo, o percurso pelo campo minado do extremismo político ao longo do qual os jovens torcedores iam colhendo o vocabulário do confronto e o exemplo da militância (Bromberger, 1995, p. 245-247), a forma de associação e o padrão de comportamento, a "simbologia correspondente à imagem de dureza que desejavam dar de si próprios" (Roversi, 1992, p. 49). Iniciado nos últimos anos da década de sessenta e nos primeiros da de setenta, o itinerário seguido pelo movimento atravessara as barricadas erguidas pelos estudantes nas ruas de Milão contra a "repressão policial"; contornara as paralisações nas fábricas de Turim decretadas pela classe trabalhadora que ansiava ingressar no paraíso da sociedade de consumo; cruzara o caminho dos "manifestantes anarquistas" que apedrejaram, na cidade de Cagliari, a comitiva do papa Paulo VI, como forma de protesto contra a ostentação do luxo na "região mais miserável" do país; fora contemporânea da "era do terrorismo" inaugurada pela bomba de teor fascista colocada no dia 12 de dezembro de 1969 no saguão do Banco Nacional da Agricultura, localizado na praça Fontana, em Milão, com dezesseis mortos e oitenta e quatro feridos. ${ }^{12}$

As torcidas ultras surgiram, dessa maneira, em meio às rebeliões estudantis e às greves operárias, entre bombas e atentados, articuladas, de uma maneira ou de outra, às matrizes ideológicas do extremismo político. Nesse sentido, enquanto a curva à direita conduzia ao núcleo composto pelas torcidas da Inter, da Lazio e

\footnotetext{
${ }^{11}$ Cf. De Santis: la giustizia sportiva ti ha assolto... la nostra ti ha condannato... a morte! Corriere della Sera, 22 de janeiro de 2001. Exemplo de citação erudita encontra-se na eliminação do Milan na Copa dos Campeões. Após perder para o Galatasaray, da Turquia, a curva Sul expôs uma faixa na qual aludia ao poema Cinco de maio de Manzoni: "Do altar à pólvora em poucos meses / por velhas dúvidas e lacunas que permaneceram suspensas". Cf. Applausi e striscioni manzoniani quella lezione scesa dalla curva. La Gazzetta dello Sport, 8 de novembro de 1999. Na temporada 2003/2004, os ultras exibiram, em vários estádios, cartazes contra a Sky, empresa de comunicação que detinha os direitos de transmissão dos jogos (cf. Foot, 2007, p. 367). Sobre as manifestações contra o doping, ver a edição de 7-13 de outubro de 1998 da revista Guerin Sportivo. O caráter "antropológico" das faixas também se encontra no Guerin Sportivo.

${ }^{12}$ Cf. Milão é palco de violência, 22 de janeiro de 1970; Itália: greve como rotina, 17 de janeiro de 1970; Em Cagliari, anarquistas atacam comitiva do papa, 25 de abril de 1970, todas as reportagens publicadas em $O$ Estado de S.Paulo. Cf. Um investimento no caos. Revista Veja, 22 de março de 1978. Cf. Le bombe senza verità. L'Espresso, 16 de dezembro de 1999.
} 
do Verona, próximas ao Movimento Social Italiano, a curva à esquerda descortinava a presença de uma série de agrupamentos que se proclamavam Panteras Alvinegras, Tupamaros, Fedayns, sem contar aquelas que, pouco depois, viriam se intitular Brigadas em referência ao partido armado identificado pela estrela de cinco pontas (Podaliri; Balestri, 1998, p. 90-93). ${ }^{13}$ No decorrer dessa primeira fase do movimento, durante os "anos de aprendizado" (Roversi, 1992, p. 46), os ultras foram incorporando e recriando modelos aparentemente tão díspares e distantes entre si quanto o dos hooligans ingleses e o dos partidos de esquerda. A síntese contraditória dessas influências podia ser observada na torcida pioneira do Milan. Ela exibia no San Siro a bandeira com a figura de Che Guevara, estampada em preto sobre fundo vermelho, enquanto as canções aludiam a outra batalha, muito diversa daquela idealizada pelo revolucionário latino-americano:

Leões armados estão marchando / Somos o Fosso dos Leões

Sangue! Violência! Fosso dos Leões. ${ }^{14}$

Os ultras, eis o ponto a ser sublinhado, não se constituem na esfera esportiva como o mero reflexo do extremismo ideológico presente na sociedade. A simbologia política, re-contextualizada no estádio de futebol, desliga-se em parte das referências originais e adquire novo significado no "ritual de confrontação" elaborado pelas torcidas rivais (De Biasi \& Lanfranchi, 1997, p. 96-99). Estas, com efeito, abandonam a condição de simples espectadores do jogo para desempenhar o papel de protagonistas do espetáculo criado por elas e desenvolvido de acordo com a "metáfora da guerra" (Dal Lago; De Biasi, 1994, p. 85). A perspectiva antropológica, portanto, reconhece a influência da política na curva, mas circunscreve-lhe o alcance, enfatizando a "autonomia da cultura" ultra, seja em relação às tentativas de cooptação da classe dirigente, seja em relação às estratégias de conversão deslanchadas pelos partidos extremistas (Bromberger, 1995, p. 153).$^{15}$ Além disso, ela atribui à violência das torcidas um caráter principalmente "simbólico e teatral" e a considera, em grande parte, domesticada pelos rituais

${ }^{13}$ De fato, o termo ultras, apropriado pelas torcidas, provinha da esfera política em que remetia à categoria do extremismo (Podaliri \& Balestri, 1998, p. 88). No início dos anos setenta, ele designava, sobretudo, a ultra-esquerda. Mas pode-se recuar ainda mais na história do vocábulo. Como recorda Antonio Roversi, os grupos terroristas franceses pieds noirs, que se opunham à independência da Argélia, eram chamados de ultras (1992, p. 44).

${ }^{14}$ Cf. Ma è San Siro o la Bósnia? L'Espresso, 10 de fevereiro de 1995.

${ }^{15}$ Como admitia um dos líderes da Força Nova, grupo neofascista fundado na segunda metade dos anos noventa, a curva convertera-se no local onde "fazemos o nosso trabalho político". Cf. Piccoli Haider crescono. L'Espresso, 12 de fevereiro de 2000. 
destinados a oferecer aos seus integrantes a ocasião de provar o pertencimento ao grupo e de reafirmar a identidade ultra (Dal Lago; De Biasi, 1994, p. 85-86). ${ }^{16}$

Já a perspectiva sociológica, embora reconheça o "componente ritual" do comportamento belicoso dos torcedores, não compartilha a interpretação segundo a qual a violência das torcidas se resolva e se defina, sobretudo, em termos de uma "batalha simbólica" (Roversi, 1992, p. 120-128). Atenta à dinâmica histórica de um movimento em contínua transformação, ela coloca em relevo o caráter polimorfo de uma ação que adquire ao longo do tempo nova forma e intensidade, outro alcance e significado (Idem, p. 46). Combinando metodologias diversas, a corrente teórica roversiana traça o quadro repleto de nuances do fenômeno, o quantifica e interpreta, assinala as linhas de continuidade e os pontos de ruptura, acompanha o seu deslocamento no espaço e a sua propagação no tempo, observa os saltos de qualidade no exercício de uma violência codificada que, amiúde, mergulha e degenera em vandalismo para logo adiante re-emergir potencializada pela política e canalizada para novos alvos (Podaliri; Balestri, 1998, p. 98). Mas não nos antecipemos.

A "estrada do antagonismo violento" pela qual enveredara o movimento desde meados dos anos setenta deixava atrás de si um rastro de bens destruídos e corpos feridos (Roversi, 1992, p. 53). Senão vejamos. Os confrontos entre as torcidas da Roma e da Lazio, em março de 1974, iniciados no interior do Olímpico, prosseguiram, após a repressão policial, nas áreas circunvizinhas ao estádio, com um cenário de guerrilha urbana: ônibus incendiados, carros revirados e lojas apedrejadas. Os embates envolvendo as torcidas do Milan e da Juventus, em fevereiro de 1975, começaram nas arquibancadas opondo as duas facções do rubro-negro, os militantes do Fosso dos Leões versus os do Commandos Tigre, e terminaram no entorno do San Siro com um torcedor da equipe de Turim esfaqueado (Idem, p. 17/50). As autoridades, por sua vez, reagiram à escalada da violência implantando, a partir de 1977, uma série de medidas de repressão, em especial a rígida divisão das torcidas dentro dos estádios (Podaliri; Balestri, 1998, p. 93). Estas, em contrapartida, responderam com o deslocamento dos confrontos para áreas livres do controle policial, enquanto aceleravam o processo já em curso da militarização, consubstanciado na adoção de uma "lógica de guerra" que as levava a planificar com antecedência a escolha do lugar da luta, a calcular

\footnotetext{
${ }^{16}$ As demonstrações dos torcedores objetivam acima de tudo "produzir uma impressão de violência para desestabilizar o adversário" e afirmar, em contrapartida, "a superioridade" do próprio grupo; apenas "ocasionalmente degeneram em atos brutais" (Bromberger, 1995, p. 242).
} 
o momento certo da ação, a delinear previamente a tática a ser empregada no combate, travado, doravante, fora das praças esportivas (Roversi, 1992, p. 55).

A segunda fase do movimento, delimitada pelos últimos anos da década de setenta e a metade da de oitenta, tornara, porém, imperativa a discussão acerca das "regras do jogo" no qual as torcidas se achavam envolvidas (Idem, p. 126), principalmente após a morte de Vincenzo Paparelli, ocorrida em 28 de outubro de 1979. Adepto da Lazio, simples pai de família, ele aguardava ao lado da esposa o início do derby quando foi atingido, na curva Norte do Olímpico, por um razzo disparado da curva Sul onde se encontrava a torcida da Roma. ${ }^{17}$ Não por acaso o derby da capital era considerado pelas autoridades como a partida de mais alto risco no futebol italiano (Idem, p. 30). O episódio, no entanto, explicitava a necessidade de definir as armas, os atores e as circunstâncias da luta. Antonio Roversi teve acesso, à época, a uma "espécie de circular interna" redigida por integrantes do movimento com o intuito de estabelecer os ditames do comportamento ultra:

Não se tocam nas mulheres, nos velhos e como quer que seja não se confronta quem não tem nada a ver e não tem a possibilidade de se defender (1992, p. 55).

Visto por esse prisma, a "horda de bárbaros embriagados", segundo o estereótipo veiculado pelos meios de comunicação, transfigurava-se em uma "comunidade moral" (Idem, p. 10) edificada com base em um repertório próprio de regras, dotada de mecanismos simbólicos de integração dos jovens reunidos na "cultura da curva", na qual, decerto, a violência desfrutava de um lugar privilegiado, mas não se revestia de uma forma caótica nem se desenvolvia de modo aleatório. Ao contrário, ela se desenrolava no quadro das rivalidades e das alianças tecidas entre os diversos agrupamentos e de acordo com o código de comportamento aceito e partilhado pelos torcedores (Idem, p. 127). Nesse sentido, a torcida ultra se revelava uma das poucas "agências de socialização" em condições de oferecer aos jovens a possibilidade de assumir e desempenhar o papel adulto talhado segundo um conjunto definido de "normas, valores, sensações, crenças, razões e modelos de ação" (Idem, p. 93).

Todavia, as tensões acumuladas no bojo de um processo paradoxal, que imprimia sucessivos saltos de qualidade ao exercício da violência ao mesmo tempo em que procurava mantê-la dentro dos estreitos limites de uma "guerra ritualizada" (Bromberger, 1995, p. 266), precipitaram o movimento na direção

${ }^{17}$ Cf. Spunta un altro striscione vergognoso. La Gazzetta dello Sport, 7 de maio de 2001. O razzo é uma espécie de fogo de artifício semelhante aos sinalizadores utilizados com fins militares. 
da terceira fase de sua história, caracterizada pela fragmentação do universo ultra e pelo desregramento crescente do comportamento beligerante (Roversi, 1992, p. 126). ${ }^{18}$ Prenúncio das mudanças decisivas que a partir de meados dos anos oitenta viriam alterar as relações de poder na curva, ao lado do retrato de Che Guevara, cultuado pelos grupos hegemônicos, apareciam agora bandeiras com a efígie de Alex, a personagem central da Laranja Mecânica, referência para os novos grupos que se proclamavam Estado de Embriaguês, Loucura Contínua ou, ainda, Desequilibrados (Podaliri \& Balestri, 1998, p. 95).$^{19}$ Entretanto, antes de fazer sua aparição triunfal nos estádios de futebol, o modelo de ação que a personagem do filme encarnava para determinados setores da juventude já operava nos interstícios da sociedade, como se infere do episódio registrado pelo correspondente em Roma de O Estado de S.Paulo:

Os italianos estão chocados com o inexplicável assassínio de um cidadão somali de 34 anos, morto enquanto dormia no pórtico de uma igreja na Piazza Navona, por quatro jovens que jogaram gasolina sobre seu corpo e the atearam fogo. ${ }^{20}$

Os jovens em questão, dois estudantes e dois trabalhadores, entre 19 e 24 anos, haviam cometido o crime por "simples divertimento". A reportagem não indicava naquele momento qualquer relação entre a dimensão racial da violência, a ideologia do grupo que a praticara e o universo em mutação dos ultras. Não obstante, no decorrer dos anos oitenta, os três fatores foram pouco a pouco convergindo e se entrelaçando na trama complexa do racismo, convertida já no decênio seguinte na "ferida aberta na sociedade" (Foot, 2007, p. 359), fustigada pela ascensão da extrema direita, cada vez mais presente e ativa nos estádios onde as novas gerações de ultras ingressavam atraídas pela atmosfera de excitação dos confrontos, seduzidas pela mitologia do nazi-fascismo, dispostas a romper com a

\footnotetext{
${ }^{18}$ Seguimos a periodização das três fases formulada por Antonio Roversi: a primeira composta pelos anos de aprendizado (1970-1977); a segunda caracterizada pela lógica da guerra e pelas regras do jogo (1977-1983-85); e a terceira definida pela multiplicação dos grupos, pela fragmentação da curva e pelo "processo degenerativo" do comportamento belicoso (1992, p. 64). Carlos Podaliri e Carlos Balestri estabelecem, ainda, uma quarta fase para o movimento, assinalada pela morte de um torcedor do Genoa, em janeiro de 1995, esfaqueado nas imediações do estádio de Marassi, por ocasião da partida contra o Milan. O episódio recolocava em discussão a necessidade de restaurar o código de comportamento dos grupos tradicionais (1998, p. 97-98).

${ }^{19}$ O impacto do filme de Stanley Kubrick, realizado em 1971, antecedia, obviamente, o período enfocado para as torcidas ultras e se estendia para muito além das curvas. Baseado no livro de Anthony Burgess, publicado em 1962, contribuíra, junto com a obra literária, para a difusão do "culto à violência" e para o aprendizado de um "estilo de agressão" entre os grupos jovens, conforme reconhecia o escritor inglês. Cf. Arte e violência. Folha de S.Paulo, 27 de maio de 1993.

${ }^{20}$ Cf. Crime horroriza italianos. O Estado de S.Paulo, 24 de maio de 1979.
} 
ordem normativa instituída pelas torcidas históricas (Roversi, 1992, p. 61). Sob o impacto conjugado desses fatores, a unidade da curva ruía e se estilhaçava em uma miríade de pequenos grupos: alguns de existência autônoma que se consolidavam imbuídos do propósito de criar novas formas de sociabilidade (Bromberger, 1995, p. 243); outros, no entanto, de existência mais errática e efêmera, sem qualquer outro propósito a não ser esquadrinhar o território à espera de uma chance para o exercício da violência, sem consideração pelo equilíbrio das forças em combate, decididos a empregar todas as armas para abater o inimigo cuja identidade a encenação promovida em Verona desvelava sem disfarce. Detenhamo-nos na descrição e análise desta peça, pois ela retrata e cristaliza o momento em que uma nova metáfora passava a dominar a cultura ultra. ${ }^{21}$

No domingo, 28 de abril de 1996, para protestar contra a iminente contratação do atleta holandês Maickel Ferrier, torcedores do Verona mantiveram na curva Sul do estádio Bentegodi, durante a partida contra o Chievo, um boneco de pano, de cor preta, com uma corda amarrada ao pescoço que dois ultras encapuzados de branco seguravam, à maneira dos algozes da Ku Klux Klan. Vestido com o uniforme da equipe, o referido fantoche trazia na camisa a mensagem política inscrita em inglês: "Negro go away". A "macabra representação", como a denominara o Corriere della Sera, levada a cabo no setor do estádio onde se concentravam as torcidas do Verona, tanto a tradicional Brigate Gialloblù, fundada em 1971 e baseada no modelo inglês, isto é, coros e cantos sem o auxílio de instrumentos musicais (Roversi, 1992, p. 45), quanto as mais recentes, vinculadas à terceira fase do movimento ultra, como a Hooligans Teddy Boys, foi coroada de êxito à medida que a direção do clube acabou demovida do propósito de contratar aquele que seria o primeiro jogador negro da equipe. ${ }^{22}$

A peça, definitivamente, não se enquadra na "armadura" convencional do “espetáculo esportivo", alicerçada, de um lado, na lógica militante e partidária das torcidas envolvidas na confrontação agonística que "reclama" sempre e cada vez mais o "descrédito do adversário"; e, de outro lado, na lógica do "descontrole controlado das emoções" que a esfera do lazer proporciona, e permite, em uma sociedade submetida aos processos de racionalização e orientada pelos códigos de comportamento civilizado (Bromberger, 1995, p. 264-265; cf. Elias, 1992, p. 146). Ela não se encaixa nesta moldura analítica por dois motivos principais: em

\footnotetext{
${ }^{21}$ A pesquisa de Antonio Roversi permite identificar o momento no qual ocorre a mudança. Segundo o autor, a maior parte das sanções impostas às torcidas ultras na temporada 1989/1990 teve como principal causa o conteúdo racista e ofensivo das faixas exibidas nos estádios (1992, p. 33).

${ }^{22}$ Cf. Precedenti. Corriere della Sera, 2 de fevereiro de 2000.
} 
primeiro lugar, porque condensa e afirma valores incompatíveis com os ideais democráticos que sustentam a "armadura" do espetáculo e determinam o talento artístico e a capacidade técnica como os únicos critérios válidos para sancionar, ou não, a presença de alguém dentro das quatro linhas (Ehrenberg, 1991, p. 38); em segundo lugar, porque o adversário em questão pertencia à equipe da torcida envolvida na aludida teatralização, dado imprevisto que não se deixava traduzir na "linguagem" de uma rivalidade "inscrita no coração da lógica do jogo" (Bromberger, 1995, p. 264). ${ }^{23}$ Uma nova lógica começava a se desenhar no futebol italiano. Ela embaralhava as regras do ritual elaborado pelas torcidas e religava os símbolos exibidos nas curvas aos pontos de referência localizados nas ruas. $\mathrm{O}$ deslocamento ideológico no universo dos agrupamentos ultras, com efeito, avançava pari passo com a mudança na correlação de forças na sociedade italiana. Os dois movimentos reforçavam-se reciprocamente e possuíam como ponto de convergência a rejeição à figura da alteridade, conforme deixava entrever a reportagem de La Gazzetta dello Sport:

Quatro extremistas de direita, ultras romanistas da "Oposta Facção" tentaram na noite de domingo para segunda incendiar uma dezena de imigrantes que habitualmente encontravam proteção numa passagem subterrânea próxima a San Lorenzo, em Roma. ${ }^{24}$

Os que procuravam lugar nos subterrâneos da sociedade da abundância, percorrendo suas passagens, explorando suas brechas, viam-se face a face com as forças redivivas da intolerância racial, materializadas, por um lado, na ação criminosa perpetrada na calada da noite contra imigrantes pobres, e, por outro lado, na perseguição implacável movida à luz do dia aos jogadores negros. ${ }^{25}$ Enquanto a classe dirigente explorava com avidez crescente o mercado global, e celebrava a livre circulação de atletas estrangeiros, inclusive africanos, a extrema-direita se empenhava em criar-lhes um ambiente infernal nos estádios de futebol. O malestar na civilização do calcio escancarava as ambiguidades e incongruências de um espetáculo que não podia prescindir dos trabalhadores egressos da periferia do sistema esportivo, ao mesmo tempo em que os expunha à reação exasperada de setores militantes da plateia, cada vez mais identificados com as bandeiras

\footnotetext{
${ }^{23}$ De acordo com Christian Bromberger, nesse caso, quando o descrédito do adversário se volta contra o atleta da própria equipe, a ideologia se sobrepõe ao jogo, como ocorria, por exemplo, na Inglaterra (1995, p. 295).

${ }^{24}$ Cf. Ultras tentano di dare fuoco a immigrati. La Gazzetta dello Sport, 21 de março de 2000.

${ }^{25}$ Como sublinha Aristide Zolberg, os imigrantes eram "necessários, mas não bem-vindos... havia uma contradição entre a presença deles como atores econômicos e o fato de que sua presença social não fosse desejada" (apud Foot, 2007, p. 359).
} 
da xenofobia e do racismo (Podaliri \& Balestri, p. 1998). As reminiscências do bicampeão mundial Amarildo, atleta brasileiro do Milan e da Fiorentina nos anos sessenta, evocavam-nas com uma nota de resignação, indicando-nos a linha de continuidade entre a curva e o campo e o elo entre o passado e o presente:

Minhas pernas são cartas geográficas. Me encheram de pancadas e insultos. Me diziam sporco negro e, tudo bem, porque o futebol também é feito de palavrões. ${ }^{26}$

Mas do que é feito o futebol? Existe uma receita natural que inclua os insultos raciais proferidos nas arquibancadas ou nos gramados? Quais são os ingredientes envolvidos em sua composição e o que a torna em determinadas conjunturas tão ameaçadora? Para abordar esta série de questões devemos abrir o mapa da intolerância racial a fim de avaliar a extensão do território abrangido por ela, seguir ao longo das fronteiras traçadas por suas linhas, acompanhar as trajetórias percorridas por aqueles que, trinta anos depois, em um contexto histórico muito mais hostil e adverso, voltavam a reviver as experiências de Amarildo. Todavia, se o mapa do calcio delineava antigas tramas de preconceito e discriminação, os jogadores negros, em compensação, traçavam novos itinerários e redefiniam a si próprios, ao mesmo tempo em que colocavam em questão a identidade dos torcedores ultras entrincheirados na curva à direita, e explicitavam as contradições dos empresários globais encastelados nos postos de poder. Eis, em suma, os atores do espetáculo. A temporada 1999/2000 os reunia e inter-relacionava em uma conjuntura explosiva. Já é hora de voltarmos a ela.

De uma ponta a outra da península, de uma curva a outra dos estádios, o exercício da violência simbólica pretendia associar de forma inextricável o corpo negro à condição infra-humana (Gilroy, 2007). Os exemplos multiplicavam-se a cada rodada. Conforme registrava a crônica esportiva, no decorrer da partida contra o Torino, no estádio Delle Alpi, os torcedores do Verona "começaram a marcar com os habituais e vergonhosos urros simiescos" as jogadas do granada Djibril Diawara, atleta senegalês de nacionalidade francesa. ${ }^{27}$ As manifestações de cunho racista repetiam-se a cada jogo e lhe despertavam a indignação: "Não se pode gritar buuh a um jogador só porque tem a pele escura. Eu não sou um animal" ${ }^{28}$ Com efeito, o duelo simbólico travado pelas torcidas durante a partida de futebol alvejava a identidade do adversário por todos os flancos e através de todos os estigmas, relegando-a "às margens da civilização" (Bromberger, 1995,

${ }^{26}$ Cf. Amarildo, fiorentino per passione. La Gazzetta dello Sport, 7 de fevereiro de 1999.

${ }^{27} \mathrm{Cf}$. Braschi se distrae. I razzisti invece no. La Gazzetta dello Sport, 26 de março de 2000.

${ }^{28}$ Cf. Diawara: "Io, trattato da animale". La Repubblica, 2 de março de 2000. 
p. 264/292). Os exercícios de classificação, no entanto, comportavam reviravoltas surpreendentes, pois os símbolos escolhidos pelas próprias torcidas as situavam, muitas vezes, aquém ou além do "domínio da cultura, das regras e da ordem estabelecida" (Toledo, 1996, p. 54-55). Nada mais emblemático nesse sentido do que a faixa aberta pelos hooligans do Manchester United: "Nós odiamos os humanos" (Roversi, 1992, p. 86). Os ultras da Lazio, por sua vez, desejavam mergulhar "na animalidade" os que encarnavam para eles uma "irredutível diferença" situada à flor da pele (Bromberger, 1995, p. 295), como demonstrava o tratamento dispensado aos jogadores negros do Parma. Saliou Lassissi, defensor da Costa do Marfim, recordava nestes termos a experiência vivida no Olímpico: "Cada vez que tocava na bola me sentia muito mal". ${ }^{29}$ Sentimento partilhado pelo colega de equipe, o atacante Ousmane Dabo, descendente de africanos, nascido na França:

Sentir aquela gente urrar contra nós, jogadores de cor, é pesado, em certos momentos chega a ser, mesmo, insuportável. ${ }^{30}$

O melhor talvez fosse "não dar importância a essas pessoas", acrescentava Lilian Thuram, o terceiro atleta do Parma implacavelmente perseguido pelos sons guturais das arquibancadas. Mas ele próprio advertia: "o problema é que o número destes torcedores é sempre crescente". ${ }^{31} \mathrm{E}$ transcendia, na verdade, o universo das curvas. A revista Guerin Sportivo via-se constrangida a admitir a respeito dos acontecimentos verificados no jogo entre Verona e Inter: "No Bentegodi os que faziam o verso do macaco a Clarence Seedorf não eram apenas os ultras. O ululado provinha também dos 'setores burgueses' do estádio". ${ }^{32}$ Lilian Thuram procurava elucidar o significado dessas manifestações nos seguintes termos: "O raciocínio deles é: os negros são como os macacos, nós urramos 'buuh' para fazê-los entender este conceito". Conforme recordava o zagueiro

\footnotetext{
${ }^{29}$ Cf. Coro razzisti, roba da 800. La Repubblica, 16 de fevereiro de 2000.

${ }^{30}$ Cf. Lassissi: "Quei tifosi cattivi e razzisti”. Dabo: "Lo stadio è il riflesso del mondo". La Gazzetta dello Sport, 16 de fevereiro de 2000. O pai de Dabo atuou pela Seleção do Senegal até se transferir, nos anos sessenta, para a França. O filho, formado nas categorias de base do Rennes, jogou na Seleção Francesa Sub-21.

${ }^{31}$ Cf. La superiorità di Thuram. La Gazzetta dello Sport, 16 de fevereiro de 2000. Considerado o herdeiro de Marius Trésor, também nascido em Guadalupe, e zagueiro do selecionado francês nas Copas de 1978, na Argentina, e 1982, na Itália, Lilian Thuram, tinha, então, 28 anos, e havia iniciado a carreira no Monaco, da França, na temporada 1990/1991, transferindo-se para o Parma na temporada 1996/1997.

${ }^{32}$ Cf. L'ultra domenica. Guerin Sportivo, 23-29 de fevereiro de 2000. Seedorf contava, então, 24 anos, e atuava naquela temporada pela Internazionale, de Milão. A trajetória profissional iniciada no Ajax, da Holanda, incluía ainda a Sampdoria, da Itália, e o Real Madrid, da Espanha.
} 
francês: "A escravidão, abolida apenas no século passado, era aceita por todos". E concluía o raciocínio de forma lapidar: "O 'buuh' de hoje é filho desta cultura". 33

Embora amplamente difundida e arraigada no imaginário social, a cultura do "buuh" estava longe de obter unanimidade nos estádios da Península, como revelava a partida entre Roma e Leeds United, válida pela Copa da Uefa. A cada vez que o jogador sul-africano Lucas Valeriu Radebe tocava na bola, os ultras romanistas lhe endereçavam os urros simiescos. De repente, porém, irrompeu o coro democrático articulado pelos cidadãos comuns presentes ao Olímpico, dispostos a substituir a condição de meros espectadores passivos para assumir a de protagonistas do drama racial. $\mathrm{O}$ atleta Damiano Tommasi recordava o episódio como um marco no combate à discriminação: "Aquelas vaias tiveram a capacidade de calar o 'buuh' racista". ${ }^{34}$ Segundo o volante da Roma, elas representaram "uma tomada de consciência" e expressaram o desejo "de fazer qualquer coisa de diferente e talvez mais eficaz" do que a proibição das faixas, o policiamento das curvas, ou a punição dos clubes, conjunto de medidas repressivas adotadas pelas autoridades esportivas e governamentais. ${ }^{35}$

A batalha dos urros e das vaias, assim, desvelava a divisão interna da sociedade italiana, polarizada entre duas visões de mundo antagônicas acerca da figura $\mathrm{da}$ alteridade encarnada pelo jogador negro. $\mathrm{O}$ teatro da bola dramatizava-lhe o dilaceramento diante de uma questão para a qual ela não tinha uma resposta satisfatória, mas face à qual sentia uma profunda vertigem pelo que comportava de ameaça e interrogação acerca da identidade coletiva, de sua coerência e unidade, de sua homogeneidade e de suas certezas (Enriquez, 1998). Para os setores da extrema direita das arquibancadas, no entanto, não se tratava de alimentar nenhum tipo de dúvida, tampouco de se colocar questões, mas tão-somente de acreditar no "poder do corpo de manter no lugar as fronteiras da diferença racial" (Gilroy, 2007, p. 42). As sentinelas estavam em alerta! Catilina Aubameyang, jogador do Gabão, contratado e cedido por empréstimo pelo Milan ao Padova para adquirir experiência no calcio, foi impedido de jogar na equipe pela facção

${ }^{33}$ Cf. La superiorità di Thuram. La Gazzetta dello Sport, 16 de fevereiro de 2000. Conforme assinala Kabengele Munanga: "nos primórdios da colonização, a África negra foi considerada um deserto cultural, e seus habitantes como o elo entre o homem e o macaco" $(2009$, p. 20).

${ }^{34} \mathrm{Cf}$. Tommasi esalta i fischi al razziismo. La Gazzetta dello Sport, 4 de março de 2000. O jogador chegou a publicar um artigo no qual aludia à frase célebre de Martin Luther King: "Também eu tenho um sonho..." Cf. A volte mi vergogno di essere un calciatore. Guerin Sportivo, 8-14 de março de 2000.

${ }^{35}$ Cf. "Lo stato si riprende le curve per razzisti e violenti è finita". La Repubblica, 5 de fevereiro de 2000. Cf. Uno striscione può costare 3 punti. La Gazzetta dello Sport, 4 de fevereiro 2000. 
neofascista da torcida, Gioventù Crociata, a qual divulgara no site da própria agremiação a palavra de ordem: "O negro não passará nem agora nem nunca". ${ }^{36}$

O interdito, porém, não constituía uma novidade no futebol italiano, nem atingia de forma exclusiva os africanos e seus descendentes. Em 1989, Ronnie Rosenthal, da Seleção de Israel, também se vira constrangido a abandonar a Udinese por causa das pichações nos muros da cidade que lhe eram endereçadas: "Rosenthal vai ao forno" e "Fora os hebreus do Friuli". ${ }^{37}$ Já os ultras da Lazio reuniram em uma única manifestação os dois principais alvos da militância racista, dedicando a Roma, no derby da capital, a faixa: "Esquadra de negros / Curva de judeus". ${ }^{38}$ Os autores da mensagem, os Irredutíveis, ${ }^{39}$ haviam homenageado um ano antes Zeljko Raznatovic, cognominado Arkan, ex-líder da torcida do Estrela Vermelha, de Belgrado, o qual se transformara posteriormente no comandante dos Tigres, isto é, do grupo paramilitar sérvio acusado de cometer genocídio contra croatas e bósnios na guerra civil da Iugoslávia. ${ }^{40}$ Assassinado em janeiro de 2000, o referido comandante recebera nos jornais de Belgrado um necrológio escrito por Sinisa Mihajlovic, jogador sérvio da Lazio. Os Irredutíveis, em solidariedade ao ídolo da equipe, estenderam na curva Norte do estádio Olímpico a faixa destinada a escandalizar a opinião pública: "Honra ao Tigre Arkan". ${ }^{41}$ A repercussão não podia ser mais negativa. Sérgio Cragnotti, zeloso da imagem da instituição que presidia, saiu a campo para defendê-la:

A Lazio sublinha que aquela minoria de torcedores age para transformar a curva em um laboratório de propaganda política e está cansada de pagar dezenas de milhões de multa por culpa de uma torcida que ora expõe bandeiras e símbolos racistas e extremistas, ora

${ }^{36}$ Cf. "Ha la pele nera e noi non lo vogliamo". Aubameyang rifiuta di andare a Padova. La Repubblica, 16 de julho de 2003.

${ }^{37}$ Cf. I precedenti. Corriere della Sera, 2 de fevereiro de 2000. De acordo com o Dossier. Raggi ultra violenti. Guerin Sportivo, 2-8 de junho de 1999, a iniciativa pertencera ao agrupamento autodenominado Holligans Teddy Boys.

${ }^{38}$ Cf. La Lazio verso la squalifica. La Gazzetta dello Sport, 1 de maio de 2001. Nesta partida, Cafu foi implacavelmente perseguido pelo "buuh".

${ }^{39}$ Os Irredutíveis surgiram na curva Norte do estádio Olímpico em 1987. Diabolik, líder do agrupamento, era simpatizante do grupo neofascista Força Nova. Cf. Ultima curva a destra. L'Espresso, 2 de dezembro de 1999.

${ }^{40}$ Zeljko adquiriu o Obilic de Belgrado e o conduziu, primeiro, ao título nacional e, logo depois, à Copa dos Campeões, causando nesse momento embaraço à Uefa que se via colocada diante de alguém que não era um simples presidente de clube, mas, como denunciava a imprensa, "responsável de genocídio". Cf. Visto per Sport. La Gazzetta dello Sport, 2 de abril de 1999.

${ }^{41}$ Mihajlovic conhecera Arkan doze anos antes quando o referido comandante era chefe de torcida. Em entrevista ao semanário Guerin Sportivo, 15 - 21 de novembro de 2000, o jogador justificou a relação com Arkan nos seguintes termos: "Era um 'amigo esportivo"”. Cf. Stranieri, conta l'anima italiana. La Gazzetta dello Sport, 30 de abril de 1999. 
faz explodir engenhos que provocam terror, e ora desfralda faixas que festejam terroristas que se tornaram responsáveis por crimes cruéis. ${ }^{42}$

O comunicado objetivava assinalar a distância entre a ação dinâmica e bemsucedida de um empresário global, cujo campo de investimento se estendia por todo o planeta e abrangia os mais diversos ramos de atividade, e o comportamento considerado arcaico dos ultras, comprometidos com o exercício de uma violência que evocava um passado sem lugar nem vez no quadro da modernização do futebol italiano. Interessada em demarcar a separação, Sergio Cragnotti trouxe para a temporada seguinte o jovem atleta de Gana, Daniel Ola, de 19 anos, para "demonstrar que não somos racistas". ${ }^{43}$ A imagem aggiornata que o presidente da Lazio desejava atribuir à sociedade esportiva, entretanto, ao invés de corresponder ao discurso que ele apregoava, ocultava, no fundo, as velhas práticas do colonialismo europeu, portadoras de uma violência tão mais ampla e profunda do que a promovida pelos ultras.

De fato, durante a Copa dos Campeões, temporada 2000/2001, a camisa da equipe estampou o patrocínio da Del Monte, empresa especializada na produção de frutas, com atuação em várias partes do globo, inclusive na África. Em cerca de cinco mil hectares de plantação, numa região localizada a cinquenta quilômetros ao norte de Nairóbi, ela extraía uma produção anual de trezentas mil toneladas de abacaxis. Submetidas em seguida ao processo de esterilização e transformadas em sucos ou vendidas em conserva, as frutas chegavam às gôndolas dos supermercados na América, Europa e Extremo Oriente. A Del Monte, no entanto, recebia uma dupla visibilidade: de um lado, beneficiava-se da campanha de uma equipe recheada de astros que mantinham a Lazio no centro do noticiário esportivo; de outro lado, sofria a campanha movida por inúmeras organizações civis que denunciavam o rastro de destruição envolvido na plantação de abacaxis. A cena reproduzia antigos horrores do imperialismo europeu: corpo de guardas nas fazendas, armados e motorizados, com cães e cavalos, a vigiar a mão-de-obra superexplorada, com salários indignos, alojamentos insalubres, submetida a toda sorte de abusos e violência, exposta, ainda por cima, aos pesticidas altamente tóxicos utilizados em quantidade maciça a fim de extrair o máximo da terra. ${ }^{44}$ Ora, o controle acionário da Del Monte pertencia a Cirio, a empresa de Sergio

\footnotetext{
${ }^{42}$ Cf. Ultrà estremisti, il calcio dice basta. La Gazzetta dello Sport, 1 de fevereiro de 2000.

${ }^{43}$ Cf. Gli ultrà della Lazio picchiano Zago. Corriere della Sera, 7 de maio de 2001.

${ }^{44}$ Cf. Chi paga gli ananas? Multinazionali in África / Il caso Del Monte - Cirio. Francesco Gesualdi, diretor do Centro Novo Modelo de Desenvolvimento, organização não-governamental de Vecchiano, Pisa. Cf. revista Nigrizia, novembro de 1999.
} 
Cragnotti. ${ }^{45}$ Enquanto se exibia na Itália como símbolo da revolução econômica do calcio, o presidente da Lazio, de acordo com as denúncias das organizações civis que atuavam no Quênia, sustentava os antigos mecanismos da exploração imperialista, dedicados a estiolar vidas e esterilizar terras, em estreita colaboração com as autoridades locais.

Não obstante, a bola continuava a rolar nos descampados de Mathare, em Nairóbi, a imensa favela na região nordeste da capital, constituída, em grande parte, por casas de lata, sem água potável nem eletricidade (Davis, 2006). Dos seus barracos saíam os atletas do time homônimo, bicampeão do Quênia. Assim como a maioria dos garotos desvalidos, George, de 15 anos, tinha abandonado os estudos e se dedicava tão-somente a correr atrás de um sonho: "Eu sou meia direita e o meu maior desejo é jogar no Mathare United, mas, se não for possível, procuro outra equipe". ${ }^{46} \mathrm{O}$ esporte bretão, com efeito, havia plantado profundas raízes no continente africano. Semeado ainda no contexto do colonialismo europeu (Stuart, 1995), assegurava, agora, frutos preciosos à classe dirigente esportiva. Em troca, esta acreditava exercer a nobre função educativa de domesticar uma prática vista como selvagem e exercida sem disciplina nem sistema, em campos de terra, sem qualquer estrutura. The Economist não encontrava explicação melhor para o fracasso do Zaire, em 1974, na Copa da Alemanha, a não ser "falta de tática e disciplina”. O semanário, porém, sublinhava a evolução do quadro:

Mas desde então as equipes africanas moderaram sua exuberância com treinamento mais rigoroso e táticas mais sutis. ${ }^{47}$

Tão benéfica mudança, obviamente, cabia aos agentes da civilização, missionários da bola encarregados de converter os nativos ao credo do futebol-força cuja expansão implicava todas as técnicas, táticas e práticas de poder exigidas pelo modelo hegemônico (Florenzano, p. 1998). Se a presença do artista negro proporcionava um sabor exótico às plateias brancas da Europa, esta, em compensação, ministrava o remédio amargo da organização racional do jogo para equipes compostas de jogadores encarados como meramente intuitivos. A natureza do intercâmbio podia ser avaliada na postura do treinador italiano contratado

\footnotetext{
${ }^{45}$ Cf. Travolto da un insolito ananás. L'Espresso, 25 de novembro de 2001. Sergio Cragnotti mantinha silêncio sobre as denúncias e deixava para o diretor de relações externas da empresa o encargo de tentar respondê-las: "É verdade que a Cirio tem a maioria na Del Monte Royal, a qual, por sua vez, controla a Del Monte Quênia, de Tikah, mas, sobre a base dos pactos parassociais, a gestão executiva diz respeito ao sócio minoritário, a sul-africana Imerman".

${ }^{46}$ Cf. Mathare, dove il pallone pulisce il mondo. La Gazzetta dello Sport, 11 de abril de 2001.

${ }^{47}$ Cf. Em busca do espírito de equipe. The Economist. In: Gazeta Mercantil, 25 de fevereiro de 2000.
} 
para dirigir a Seleção da Tunísia, em 2000, na Copa de Seleções da África. Em entrevista a La Gazzetta dello Sport, Francesco Scoglio explicava de forma didática que tipo de contribuição trouxera para os afro-árabes: "Cultura tática, capacidade de variação no jogo", mas, também, "a humildade em compreender como a constância no trabalho recompensa sempre mais do que um golpe de gênio esporádico". ${ }^{48}$ Ou seja: ao jogador despojado de razão, considerado inconstante, mas capaz de iluminar uma jogada com o talento considerado inato, a civilização europeia oferecia a disciplina do corpo, a ética do trabalho e os valores necessários para mover a engrenagem de um jogo no qual, consoante a definição de Antonio Roversi:

a racionalidade dos esquemas aplicados em campo comporta necessariamente o total sacrifício da espontaneidade e inventividade dos indivíduos a favor de uma disposição tática prudente e calculada baseada numa estratégia solidária, preestabelecida e utilitária $(1990,84)$.

Eis a concepção hegemônica exportada para os quatro cantos do mundo, cujo mérito, conforme enfatizado, consistia em moderar a exuberância do futebol praticado nas duas margens do Atlântico Sul, de onde provinha, afinal de contas, a matéria-prima utilizada pela máquina moderna desenvolvida na Europa, em cujas engrenagens operava-se a aculturação dos forasteiros. "Se não se italianiza um pouco", sublinhava La Gazzetta dello Sport a respeito do ala Serginho, "o brasileiro corre o risco de se transformar em um brinquedo de exibição". ${ }^{49}$ Dentro desta mesma visão, o periódico esportivo lamentava as vicissitudes do treinador Giuseppe Dossena, da Seleção de Gana, por vê-lo sofrer "a contestação de um povo" que lhe reprovava o modelo italiano baseado em "um jogo atlético, disciplinado e coletivo", mal adaptado àquele "pirotécnico estilo brasileiro" que no referido país se considerava mais próximo da qualidade dos jogadores africanos. ${ }^{50}$ A mesma imprensa esportiva que lamentava o fato do futebol italiano ser apreendido pela imagem distorcida do catenaccio, retratava o futebol brasileiro através do estereótipo não menos deformador do calcio-samb $a,{ }^{51}$ cuja noção embutia uma dose elevada de ironia e denotava tanto admiração quanto censura. Indiferente ao “confronto de representações” (Toledo, 2002, p. 22), a crítica de Lilian Thuram

\footnotetext{
${ }^{48}$ Cf. Scoglio 1'africano: "In Tunisia ho ritrovato 1'entusiasmo". La Gazzetta dello Sport, 9 de fevereiro de 2000.

${ }^{49}$ Cf. Serginho a scuola di retromarcia. La Gazzetta dello Sport, 3 de setembro de 1999.

${ }^{50}$ Cf. Coppa d'Africa: tra mille disagi. La Gazzetta dello Sport, 6 de fevereiro de 2000.

${ }^{51}$ Cf. Calcio-samba con il Brasile al Camp Nou. La Gazzetta dello Sport, 28 de abril de 1999.
} 
voltava-se para o modelo hegemônico que situava o "dinheiro" como o "primeiro objetivo do homem" e ignorava o "respeito pela diversidade". 52

Objeto do desejo da classe dirigente europeia, o atleta proveniente das Antilhas, da América do Sul ou da África precisava converter-se em um profissional capaz de se enquadrar nos esquemas táticos traçados pelas comissões técnicas, bem como satisfazer às expectativas de comportamento estabelecidas pelas agremiações esportivas. Em contrapartida, conforme lhe recordavam insistentemente os agrupamentos de torcedores distribuídos nas curvas dos estádios, ele não podia aceder à condição de membro pleno da sociedade que o acolhia no contexto da cultura do "buuh". O racismo e a uniformização, desse modo, revelavam-se, aparentemente, nas duas faces de uma mesma questão, tendências entrelaçadas de forma contraditória no contexto da globalização do futebol, consubstanciados, o primeiro, no recrudescimento do discurso da intolerância dos ultras de extremadireita contra a presença dos jogadores da diáspora africana, ${ }^{53}$ e o segundo, na universalização dos aparelhos de produção, responsáveis pela redução da margem de liberdade dos atores no gramado, inclusive e sobretudo a de atribuir novos significados ao jogo. Se o processo parecia expulsar de campo toda e qualquer forma de diversidade, isto se devia à abertura das fronteiras nacionais, consoante o argumento formulado por Antonio Papa e Guido Panico:

O frenético movimento migratório dos jogadores de futebol e dos treinadores em direção ao Velho Continente e no seu próprio interior é o ingrediente fundamental de uma mescla que está enfraquecendo os estilos nacionais de jogo e as imagens esportivas dos países (2000, 199).

Mas o jogo da diversidade, assinala Lévi-Strauss, "é menos função do isolamento dos grupos que das relações que os unem" (1993, p. 333). A cultura italiana do calcio e a arte brasileira do futebol desenvolveram esquemas táticos, fixaram representações e estereótipos, edificaram mitologias, ampliaram e aprimoraram o repertório de técnicas corporais, não em um regime de autarquia, mas no quadro de uma intensa comunicação, realizada por intermédio de vários canais (excursões, amistosos, competições oficiais), e mediante inúmeras categorias (repatriados, oriundos, naturalizados), forjadas para transpor os limites

\footnotetext{
${ }_{52}$ Cf. La superiorità di Thuram. La Gazzetta dello Sport, 16 de fevereiro de 2000.

${ }^{53}$ No final do século XX, cerca de mil e quinhentos atletas africanos atuavam nos mais diversos mercados do futebol, desde a China até a Colômbia, passando pelos Emirados Árabes. Cf. Il Gran Bazar di Talenti. Guerin Sportivo, 21 - 27 de julho de 1999.
} 
estabelecidos pelas fronteiras nacionais (cf. Toledo, 2002) ${ }^{54}$ Elas se constituíram, portanto, sob a forma de coligações, sempre mais fecundas à medida que novos parceiros adentraram o gramado de jogo (Lévi-Strauss, 1993, p. 358) ${ }^{55}$ Nesse sentido basta pensar nas contribuições decorrentes da inclusão do negro no futebol brasileiro, do jogador brasileiro no futebol italiano, o qual, mais recentemente, tem se beneficiado da presença do jogador africano, cuja fonte de inspiração, no entanto, encontra-se localizada do outro lado do Atlântico Sul. Não por acaso, na periferia de Lagos, o correspondente de La Gazzetta dello Sport deparou-se com a existência de um inesperado e surpreendente Maracanã, isto é, um terreno "sem arquibancada nem linhas de campo, mas onde cresceram os melhores jogadores nigerianos dos últimos anos". ${ }^{56}$

Emmanuel Amunike, Victor Ikpeba, Taribo West, dentre outros, atuaram na arquitetura imaginária do Maracanã de Lagos, percorreram os campos míticos do futebol-arte, exercitaram-se nas práticas de liberdade vinculadas a esta concepção (Florenzano, 2009), embora, sem dúvida, tenham depositado o sonho de ascensão profissional nos estádios da Europa, opção atestada pelos números da edição de 2000 da Copa de Seleções da África: dos trezentos e cinquenta e dois jogadores inscritos, cento e setenta e sete jogavam em campeonatos europeus, ao passo que, das dezesseis seleções envolvidas na competição, sete utilizavam treinadores africanos, enquanto nove recorriam aos europeus. ${ }^{57}$ De um lado, a cultura tática da civilização branca, de outro lado, as técnicas corporais do mundo negro. A disjunção entre destreza física e atividade mental (Gilroy, 2007, p. 41), levada a cabo nos aparelhos de produção dos clubes, mantinha estreita correlação com a operação que destituía o corpo negro da condição humana, associando-o à

\footnotetext{
${ }^{54}$ O modelo analítico elaborado por Luiz Henrique de Toledo revela-se de fundamental importância para a discussão do tema, em especial no que se refere às "três naturezas" do futebol, como as denomina o autor: a universalização das regras, a "primeira natureza"; a fragmentação nas formas ou padrões de jogo, a "segunda natureza"; e as representações associadas às identidades coletivas, a "terceira natureza" (2002, p. 61-62).

${ }_{55}$ Assim como na esfera mais abrangente das culturas humanas, analisada por Lévi-Strauss, também na mais específica do futebol "existem sempre tendências operando em direções contrárias por um lado, em direção à homogeneização e, por outro, em direção a novas distinções" (apud Sahlins, 1997a, p. 57).

${ }^{56}$ Cf. Nel Maracanà di Lagos, dove nascono più campioni che a Rio. La Gazzetta dello Sport, 9 de fevereiro de 2000. Segundo a revista Guerin Sportivo, cerca de 150 atletas nigerianos atuavam no final do século XX nos campeonatos europeus, êxodo iniciado em 1985 com a contratação de Stephen Keshi pelo Anderlecht, da Bélgica. A força do futebol da Nigéria se revelava na conquista de duas Copas da África, em 1980 e 1994, na medalha de ouro obtida nas Olimpíadas de 1996, e nos mundiais Sub-16 e Sub-17, arrebatados respectivamente em 1985 e 1993. Cf. Dove osano le Aquile Verdi? Guerin Sportivo, 14 - 20 de janeiro de 1998.

${ }^{57}$ Cf. Sette sorelle per una Coppa d'Africa a rischio. La Gazzetta dello Sport, 21 de janeiro de 2000.
} 
animalidade, empreendida nas arquibancadas pela extrema direita do movimento ultras. A cartografia do racismo, dessa maneira, circunscrevia a área de atuação dos jogadores da diáspora, prescrevia-lhe os papéis possíveis, depurava-lhes os excessos estilísticos, curava-os dos desregramentos e das transgressões, mas não eliminava as cicatrizes adquiridas ao longo de uma estrada muitas vezes sem volta nem linha de fuga.

Muhammed Kallon, 19 anos, nascido em Freetown, jogava sua primeira temporada no futebol italiano pelo time do Cagliari. Enquanto buscava se adaptar ao novo ambiente, acompanhava pela televisão, dilacerado, a guerra civil em Serra Leoa: "Não posso fazer nada a não ser ter pesadelos", explicava. "Os rebeldes queimaram tudo, cortaram todas as comunicações. Há duas semanas não sei mais nada dos meus familiares". A única informação obtida a muito custo assegurava que lhe haviam "queimado a casa" ${ }^{58}$ Sem poder voltar ao país de origem, convulsionado pelo conflito interno, o jogador envidava esforços para se inserir no país de adoção, o qual, por sua vez, achava-se às voltas com o recrudescimento do imaginário racista que o situava na condição de inimigo. Patrick Mboma, de Camarões, 28 anos, respondia ao dilema nos seguintes termos: "Quando estou na África me sinto africano; quando estou na Europa, me sinto europeu". ${ }^{59}$ Nascido na cidade de Douala, crescido nos arredores de Paris, o centroavante rodara o mundo, empreendendo um percurso que o levara do Sul para o Norte e do Norte para o Extremo Oriente, onde, por um ano, tivera a oportunidade de atuar no Gamba Osaka, experiência que lhe permitira "aprender a amar a cultura e os hábitos japoneses".

A Babel do futebol atraía atletas de todos os quadrantes do planeta. No caso específico dos orientais, a porta de entrada chamava-se Perugia. Por ela passara inicialmente o japonês Hidetoshi Nakata, contratado junto ao Bellmare Hiratsuka, e logo em seguida o primeiro chinês na história do calcio, Ma Mingyu, atleta proveniente do Sichuan Quan Xing. ${ }^{60}$ Nos antípodas desta política situava-se a esquadra do Piacenza. Enquanto aquela encarnava a abertura indiscriminada ao outro, mediante a presença de jogadores nacionais e estrangeiros, do mundo desenvolvido e do subdesenvolvido, brancos e negros, ocidentais e orientais, esta representava o último baluarte do nacionalismo esportivo, atuando com atletas exclusivamente italianos. Próximo da última rodada do campeonato, por ironia

\footnotetext{
${ }^{58}$ Cf. Il dramma di Kallon: la famiglia è dispersa in guerra. La Gazzetta dello Sport, 13 de janeiro de 1999.

${ }^{59}$ Cf. Mboma ridisegna il suo futuro a Cagliari. La Gazzetta dello Sport, 23 de março de 1999.

${ }^{60}$ Cf. Bucchi scalda il Perugia. La Gazzetta dello Sport, 18 agosto de 2000. Depois do japonês Nakata, e antes do chinês Ma, a equipe italiana havia contratado o sul-coreano Jung Haw Ahn, 24 anos.
} 
do destino, as duas equipes se enfrentaram em um jogo fatídico, pois a derrota do Piacenza pelo placar de 2 a 0 condenara ao rebaixamento "a única esquadra sem estrangeiros". ${ }^{61}$

A estratégia adotada pelo presidente Luciano Gaucci, do Perugia, almejava sem dúvida alguma a conquista de novos mercados consumidores, a internacionalização da marca da agremiação, a captação dos investimentos das empresas globais. A despeito do interesse comercial que a revestia, ela acabava, segundo a imprensa esportiva, por se constituir em um "manifesto antirracial" e "símbolo da tolerância". ${ }^{62}$ Sobretudo, a política posta em ação prefigurava a mudança de uma identidade coletiva representada pela presença no elenco de Fabio Liverani, filho de mãe somali e pai italiano, cuja ascensão o conduzira, no curto espaço de dez meses, da série C para a série A. Estimulado pelos elogios da crônica esportiva, ele lançava a todo o país o desafio: "Quero ser o primeiro negro da Seleção Nacional" ${ }^{63}$ Dito e feito. Como registrava La Repubblica a propósito da partida amistosa contra a África do Sul, marcada para a noite de 25 de abril de 2001:

Liverani será o primeiro jogador de pele escura a endossar o azul da Itália. ${ }^{64}$

Atuando os primeiros quarenta e cinco minutos, o "italiano de cor" colheria muitos elogios na vitória de 1 a 0 da Azzurra. ${ }^{65}$ As perspectivas profissionais pareciam as melhores possíveis e logo o meio de campo de 25 anos ascendia mais um pouco na carreira, transferindo-se do Perugia para a Lazio a fim de disputar a temporada 2001/2002. A trajetória, contudo, o levaria a se defrontar com os Irredutíveis, o agrupamento ultra que de certa maneira se colocava na condição de trincheira inexpugnável da identidade coletiva ameaçada pela alteridade que o jogador, fruto da mestiçagem, representava. De fato, já em outubro de 2001, Liverani enfrentava os xingamentos da própria torcida e se deparava com os muros do centro de treinamento pichados com mensagens que o insultavam por ser "ne-

${ }^{61}$ Cf. Piacenza, l'Italia in serie B. La Gazzetta dello Sport, 17 de abril de 2000.

${ }^{62} \mathrm{Cf}$. reportagem citada na nota anterior.

${ }^{63}$ Cf. L'Angelo dalla faccia sporca. Guerin Sportivo, 7 - 13 de fevereiro de 2001.

${ }^{64}$ Cf. "Io italiano di colore arrivato in Nazionale". In: www.repubblica.it, 20 abril de 2001. Antes de Liverani, Joseph Dayo Oshadogan, mãe italiana e pai negeriano, havia jogado pela Nacional, mas na categoria Sub-21. Ele recorda assim essa estreia: "tive uma emoção especial. Chorava. Dentro tinha o orgulho de representar a esquadra do meu país". Cf. "Sono un italiano, un italiano nero". Guerin Sportivo, 28 de março - 4 de abril de 2000.

${ }^{65}$ A categoria do "italiano de cor" começava a adquirir visibilidade no calcio. Além de Fabio Liverani, do Perugia, e Dayo Oshadogan, da Reggina, havia mais quatro jogadores em atuação na temporada 1999/2000, dentre os quais, Christian Manfredini, do Genoa, nascido na Costa do Marfim e adotado por uma família italiana. Cf. reportagem citada na nota anterior. 
gro e romanista" ${ }^{66}$ A figura insidiosa que o atleta encarnava para os irredutíveis da identidade racial pode ser apreendida à luz das considerações de Paul Gilroy:

Pessoas diferentes são certamente odiadas e temidas, mas a antipatia oportuna contra elas não é nada comparada com os ódios voltados contra a ameaça maior representada por aquele que é meio-diferente e em parte familiar. Ter-se misturado é ter sido partidário de uma grande traição (2007, p. 132).

Dessa maneira, acusados de traidores, classificados como inimigos, e despojados da condição humana, os jogadores negros viam-se diante da dupla necessidade de superar os adversários dentro das quatro linhas e de combater os inimigos posicionados nas arquibancadas. Além da habilidade técnica, o contexto histórico exigia deles a destreza simbólica (Sahlins, 1997, p. 62). A de Lilian Thuram, zagueiro do Parma, consistia em se esquivar dos estigmas e insultos proferidos pelos ultras de extrema direita através da elaboração de uma identidade inspirada na diáspora africana. Proveniente de Guadalupe, criado nos subúrbios de Paris, ele encontrava inspiração nos ensinamentos de "Muhammad Ali, Martin Luther King, Malcolm X", isto é, de ativistas que lutaram em diversas esferas da vida social para "defender a dignidade do negro". ${ }^{67}$ A linha de passes com personagens que historicamente divergiram a respeito do melhor caminho a trilhar na luta contra o racismo o estimulava a propor e defender o caminho de Parma, indicado por ele na entrevista concedida ao semanário Guerin Sportivo: "Sonho com um mundo no qual sejamos todos iguais na própria diversidade". ${ }^{68}$

A destreza simbólica de Clarence Seedorf, em contrapartida, achava-se expressa na conferência pronunciada em um teatro de Milão para alunos do ensino médio: "Quando me perguntam da onde sou, respondo que sou do mundo. Nasci no Suriname, com dois anos fui para a Holanda, depois vivi na Espanha e na Itália, amanhã posso estar na Tailândia". Conforme argumentava o atleta da Internazionale: "a cor da pele não importa", e, sim, "o que você é como pessoa". ${ }^{69} \mathrm{O}$ que ele era ligava-se ao avô Fredericks Seedorf. O nome pertencia ao proprietário

${ }^{66}$ Cf. Lazio, ancora scritte razziste: "Liverani negro e romanista". Corriere della Sera, 11 de outubro de 2001. Numa entrevista ao semanário Guerin Sportivo, 7 - 13 de fevereiro de 2001, Liverani havia assumido a sua condição de "torcedor da Roma" Cf. L'Angelo dalla faccia sporca.

${ }^{67}$ Cf. La superiorità di Thuram. La Gazzetta dello Sport, 16 de fevereiro de 2000.

${ }^{68}$ Cf. United Colors of Lilian. Guerin Sportivo, 27 de janeiro - 2 de fevereiro de 1999.

${ }^{69}$ Cf. Seedorf insegna a battere il razzismo. La Gazzetta dello Sport, 9 de fevereiro de 2001. O Suriname afigurava-se um celeiro de jogadores. No país nasceram Edgar Davids e Clarence Seedorf. Outros, como Patrick Kluivert e Ruud Gullit, nascidos na Holanda, eram filhos de jogadores do Suriname. Cf. Le miniera dei tulipani Neri. Guerin Sportivo, 7 - 13 de julho de 1999. 
alemão de escravos e fora transmitido de geração para geração. Certas coisas, dizia o jogador, "você traz dentro e sabe de onde vem". Em busca das origens, o jogador estivera na Jamaica "para visitar as vilas dos escravos" e conhecer as histórias que "fazem você se emocionar e indignar". ${ }^{70}$ A destreza simbólica, neste caso, consistia em afirmar a identidade global de quem se pensava como cidadão do mundo, sem esquecer, no entanto, as referências contidas no ponto de partida.

Com efeito, estratégias distintas de enfrentamento do racismo, mas não mutuamente excludentes, pois a universalidade postulada por Seedorf não o levava a esquecer a descendência de escravos africanos, assim como a diversidade defendida por Thuram não o conduzia a se encerrar nos limites da comunidade com a qual se identificava (Munanga, 2009, p. 21). ${ }^{71}$ Cada um a sua maneira, eles transitavam pela estrutura planetária do futebol elaborando a arte de se desvencilhar do signo de uma alteridade evocada pelos urros simiescos dos ultras de extrema direita, redefinindo-se ao longo do percurso enquanto jogadores interculturais (Sahlins, 1997b, p. 129), dispostos a propor um novo tipo de vínculo entre a curva e o campo, abertos à troca de experiências na Babel do futebol.

\section{Referências bibliográficas}

BROMBERGER, C. Le match de football: ethnologie d'une passion partisane à Marseille, Naples et Turin. Paris: Éditions de la Maison des Sciences de l'Home, 1995.

COSTA, M. R. da. Os carecas do subúrbio: caminhos de um nomadismo moderno. São Paulo: Musa Editora, 2000.

DAVIS, M. Planeta favela. São Paulo: Boitempo, 2006.

DAL LAGO, A; DE BIASI, R. Italian football fans: culture and organization. In: GIULIANOTTI, Richard et. al. (org.). Football, violence and social identity. London and New York: Routledge, 1994.

DE BIASI, R; LANFRANCHI, P. The importance of difference: football identities in Italy. In: ARMSTRONG, Gary e GIULIANOTTI, Richard (org.). Entering the field: new perspectives on world football. Oxford / New York: Berg, 1997.

EHRENBERG, A. Le culte de la performance. Paris: Calmann, Levy, 1991.

ELIAS, N. A busca da excitação. Lisboa: Difel, 1992.

ENRIQUEZ, E. O judeu como figura paradigmática do estrangeiro. In: KOLTAI, Caterina (org.). O estrangeiro. São Paulo: Escuta / Fapesp, 1998, p. 37 - 60.

${ }^{70}$ Cf. Manifesto della diversità. La Gazzetta dello Sport, 21 de outubro de 2001.

${ }^{71}$ Conforme assinala Kabengele Munanga: “A negritude fornece, nesses tempos de globalização, um dos melhores antídotos contra as duas maneiras de se perder, por segregação cercada pelo particular e por diluição no universal" (2009, p. 21). 
FLORENZANO, J. P. A democracia corintiana: práticas de liberdade no futebol brasileiro. São Paulo: Educ/Fapesp, 2009.

FLORENZANO, J. P. Afonsinho e Edmundo: a rebeldia no futebol brasileiro. São Paulo: Musa Editora, 1998.

FOOT, J. Calcio (1898 -2007). Storia dello sport che ha fattol'Italia. Milano: Rizzoli, 2007.

GILROY, P. Entre campos: nações, culturas e o fascínio da raça. São Paulo: Annablume, 2007.

LÉVI-STRAUSS, C. Raça e história. In: Antropologia estrutural 2. 4. ed. Rio de Janeiro: Tempo Brasileiro, 1993.

MUNANGA, K. Negritude: usos e sentidos. 3. ed. Belo Horizonte: Autêntica Editora, 2009.

PAPA, A e PANICO, G. Storia sociale del calcio in Italia: dal campionati del dopoguerra alla Champions League (1945 - 2000). Bologna: Il Mulino, 2000.

DUNNING, E; MURPHY, P.; WILLIAMS, J. Il teppismo calcistico in Gran Bretagna: 1880-1989. In: ROVERSI, Antonio (org.). Calcio e violenza in Europa. Bologna: Il Mulino, 1990.

PODALIRI, C e BALESTRI, C. The ultràs, racism and football culture in Italy. In: BROWN, Adam (org.). Fanatics! Power, identity \& fandom in football. London and New York: Routledge, 1998, p. 88 - 100.

ROVERSI, A. Calcio e violenza in Europa. Bologna: Il Mulino, 1990.

ROVERSI, A. Calcio, tifo e violenza; il teppismo calcistico in Italia. Bologna: Il Mulino / Contemporanea, 1992.

SAHLINS, M. O "pessimismo sentimental" e a experiência etnográfica: por que a cultura não é um "objeto" em via de extinção (parte I). Mana. Estudos de Antropologia Social. Museu Nacional / Universidade Federal do Rio de Janeiro, volume 3, número 1, 1997, p. 41 - 73.

SAHLINS, M. O "pessimismo sentimental" e a experiência etnográfica: por que a cultura não é um "objeto" em via de extinção (parte II). Mana. Estudos de Antropologia Social. Museu Nacional / Universidade Federal do Rio de Janeiro, volume 3, número 2, 1997b, p. 103 - 150.

STUART, O. The Lions Stir: football in African society. In: WAGG, Stephen. Giving the game away: football, politics and culture on five continents. London and New York: Leicester University Press, 1995.

TOLEDO, L. H. de. Lógicas no futebol. São Paulo: Fapesp/ Hucitec, 2002.

TOLEDO, L. H. de. Torcidas organizadas de futebol. Campinas, SP: Autores Associados/Anpocs, 1996.

Recebido: 17/12/2009 - Aprovado: 24/05/2010 